\title{
Study on the Level Value Standard of the Robot Appearance Interface Factor for User Experience Design
}

\author{
Seung Eun Chung ${ }^{1}$ and Han Young Ryoo ${ }^{2, *}$ \\ ${ }^{1,2}$ Division of Digital Media, Ewha Womans University, 52, Ewhayeodae-gil, \\ Seodaemun-gu, Seoul 03760 Republic of Korea \\ ${ }^{1}$ ilovechse@ewha.ac.kr, ${ }^{2}$ hyryoo@ewha.ac.kr
}

\begin{abstract}
This study aims to establish the robot's external appearance interface design factor level values, which give meaningful differences in user experience, by clarifying the standards for the level values. The standards of the level values for the core design factors of the external appearance interface were summarized through the reference studies, and level value cases were summarized through case study analysis. Lastly, the existence of meaningful differences from the values derived through the reference studies and case study analysis in terms of user experience were investigated. As a result of the research, it was found that 'prototype categorization, 'visual realization', 'level of body materialization', 'level of body components materialization', 'proportion of body components', 'height compared to user', and 'width compared to user', that are researched as the standards for dividing the level values, show differences in user experience, so they should be utilized as important categorizing factors. When the detailed level values that were divided with above standards do not show a meaningful difference in user experience, they were merged, and among the researched 27 subordinate level values, three level values were deleted and re-summarized into 24 level values. This study has a significance as a base study that systematizes the robot interface design factors in terms of user experience.
\end{abstract}

Keywords: Social Service Robot, Appearance Interface, Design Factors and values, User Experience

\section{Introduction}

With maturation of robot-based technologies and expansion of personal robot service market, there is a growing needs for development and standardization of common foundation technologies related to robot industry. Especially, not like the industry robots, the intelligent service robots interacts with humans in everyday life, the study of the usercentered robot interface design became very significant. Interface design starts with categorizing interface design factors, so systematizing the classification standards of design factors needs to be considered as a base study for robot design. However, as an early design study of the early industries, the robot interface design studies are usually conducted on individual context and individual factor, the detailed factors and the evaluation points on those vary. In order to systematize the design factors, the commonly covered core factor standards and evaluation standards needs to be defined.

The appearance interface of robot is the part that determines the expectation and impression of the robot when user encounters the robot for the first time[1], and it considers joint structure, proportion, joint representation method, and total image property from the outer shape, structure and size perspective[2]. The existing studies on the

Received (October 7, 2017), Review Result (January 10, 2018), Accepted (February 1, 2018)

* Corresponding Author 
appearance interface are focusing on appealing the character of robot or expressing robot's appearance and functional properties. Recently, as the social service robot market emerges, studies on how humans emotionally feel about robot's appearance factors are also emerging. These studies show the relation between the robot appearance and user expectation on functions and services or emotional expectation. However, these studies only conducted on some user experience properties and not from the perspective that user experience is integrated. User experience includes product-centered level, which is related to product evaluation and distinction, interaction-centered level, which is related to action properties between human and the product, and person-centered level, which is related to emotional and resulting experience and the associated properties[3]. Thus, in terms of systematization of design factors, the functions and services based on the characteristics of the robot, the interaction in the process of using it, and the user experience that includes emotional and resulting aspects that human receive need to be all measured. In the user experience design, designer selects design factors and determines the presentation level are all based on the user experience perception. For design components, classifying systematization from giving the level of giving differences to user experience should be preceded.

This study aims to establish the robot appearance interface design factor level values, which give meaningful difference in user experience, by clarifying the standards for the level values. The level value standards for the core design factors of the appearance interface will be summarized through the reference studies, and the trend-reflected level values will be summarized through service robot case study. Lastly, we will investigate on user survey on the determined values, and provide the classification standards of the level values and detailed level values that give significant differences in terms of user experience.

\section{Robot Appearance Interface Design Factor Systematization}

\subsection{Study on Level Value Criteria for Appearance Interface Design Factor Type Classification}

This study conducted the reference study in order to understand the commonly discussed core factors and classify the types of appearance interface factors.

In the study of the shape factor which refers to the overall external appearance, Haring, Watanabe and Mougenot(2013) grouped robots into Pet robot / Service robot / Humanoid robot / Android robot type by shapes. Pet robot type has appearance of pets or animals, Service robot type is in a shape optimized to clearly accomplish the service task, Humanoid robot type generally has human characteristics except details such as skin, hair or eye lashes, and Android robot type refers robots with human Doppelgaenger looking[4]. This classification is interpreted from the categorization of prototype. Prototype is the most typical example that represents the class and is determined by common feature and Goal-relevant attribute. In addition, Realism factor affects to classifying Humanoid robot and Android robot type.

Fong(2003) classified robots into anthropomorphic, zoomorphic, caricatured and functional types. Caricatured type has exaggerated representation of certain character of robot, and it covers the level that cannot be included in a specific area such as human or animal[5]. This can be seen as a distinction on the appearance caused by changes of the detail factor on the way of visual realization.

In this way, the shape of robot also covers the discussion on the classification of level of realization. Bartneck and Forlizzi(2004) classified robots into abstract / biomorphic(mimicking a lifelike object) / anthropomorphic(mimicking a human)[6], and Blow et al., (2006) classified robot appearance in a three-dimensional design space 
which is divided into Realistic Objective / Iconic Subjective / Abstract[7]. Realism factor and Detail factor are in effect.

A structural factor is a property that a part or a factor forms a whole. In robot structure, the body type of robot structured with body components is an important factor that helps user recognizing the robot type[8]. Yu, Kwak and Kim(2007) mentioned that it is efficient to index the ratio of item value based on typical items from robot's impression to body parts. Especially, as a vertical element, the proportion between head and height is very important factor to recognize the age[9]. Their study is on the Humanoid robot, the human type robot which more diversely uses human body components, but as there are differences on the body components depending on the prototype of the robot, utilizing typical component proportion can be considered.

Robot's body components are divided into joint factors, and the level of joint classification changes the body component expression. Paiva, Leite and Ribeiro(2012) classified robots with the joint expression actualization level, High expressive articulation-Low expressive articulation[10], and this shows that detail factor also affects the structural factor.

The size factor which refers to robot's physical size, is determined in consideration of operational stability, user convenience, and psychological stability[11]. Studies on the robot size show that the user perceives the size of robot the relative height to the user: not by the absolute size but by the relative size[11][12]. The size of robot is often decided on the engineering perspective considering the stability and technical feasibility[13], but from the user perspective, the size should be decided considering relative relationship with the user.

In this study, studies that categorized the detail levels of appearance interface shape, structure, size factors were reviewed. Depending on study, classified detail level differed, but based on commonly discussed standards, the classification standards are summarized in order to explain all types of robots that are currently available.

\section{Table 1. Level Value Standard Derived from Appearance Interface Core Classification Factors}

\begin{tabular}{|c|c|c|}
\hline Factor & Classification Factor & Level Value Standard \\
\hline \multirow{2}{*}{ Shape } & Prototype, Realism, Detail & Prototype categorization \\
\cline { 3 - 3 } Structure & $\begin{array}{c}\text { Detail, } \\
\text { Joint structure and joint } \\
\text { presentation }\end{array}$ & Visual realization \\
\cline { 3 - 3 } & Body component proportion & $\begin{array}{c}\text { Materialization of body } \\
\text { components }\end{array}$ \\
\cline { 3 - 3 } Size & Relative relation with user & Proportion of Body components \\
\cline { 3 - 3 } & & Height compared to user \\
\hline
\end{tabular}

\subsection{Level Value through Case Study}

Next, with the standards of the level values derived from reference studies, level values are organized into detailed level values that can include current robot trends.

Shape factor is divided into 'categorization of archetype' and 'visual realization' by separating Prototype factor and Realism-Detail factor. According to reference studies, the visual realization is classified as Realistic / Iconic / Abstract based, but in case of 'Abstract', there is an issue that 'functional object' and 'object with geometric level form, but the prototype is known' are collected together. Since 'functional object' can be explained in the boundary of the categorization of prototypes, in separation of visual realization level value, we decided to combine it with 'object with geometric level form, but the prototype is known'. Thus, the level 
value changed from 'Abstract' to 'Symbolic'. In other word, 'Appearance characteristics almost abstracted so prototype is symbolically understood-level'.

In the structure factors, 'Materialization of body' is largely about head, body, arms, and leg element structure, and recently many simplified service robot launched and there are robots without separating head from body launched a lot as well. Legs were omitted in many cases; especially the legs are used as moving parts and sometimes represented as wheels, and wheel parts are hidden in the legs or sometimes displayed outside. In this case, legs are omitted or two legs are expressed as one simplified form. Including these level values, this is categorized into four exclusive levels.

'Materialization of body components' is about the formation of detail factors such as elbow, hand, and fingers, it is interpreted as an important factor to perceive overall detail of appearance. In this study, using the arm part as a typical example, the level values were classified by the number of joint closely materialized to the prototype. For later use, it is possible to define the level values by how closely expressed the joint components to what the prototype originally has, even if it is not the arm part.

The proportion of head and height was measured for 'proportion of body components'; in case of human, infant's head and height ratio was $1 / 4$, and as it is reduced with the growth, adult has a ratio of about $1 / 8$. However, for the cases of robot, more than half falls into $1 / 2$ to $1 / 3$ ratio[14], so the levels were categorized accordingly.

'Height compared to user' categorized user body's vertical joint height(ankle, knee, waist, shoulder, height) and 'width compared to user' categorized horizontal joint width(face, shoulder). As a result of case study, various size of robots from $10 \mathrm{~cm}$ toy robot to a robot taller than human are collected. Even though more than half of them has height in between human ankle and knee[14], but in order to include all types, detail values were all divided based on major joints. The absolute value can change in later use, but the typical man and woman standard average body size was utilized.

Appearance interface cases of social service robot were collected and analyzed, and level value definition and one to three case image per one level value were summarized. Total 27 level values and 79 cases are summarized.

Table 2. Appearance Interface Level Value Definition and Cases

\begin{tabular}{|c|c|c|c|c|c|c|c|}
\hline Factor & $\begin{array}{l}\text { Classificat } \\
\text { ion } \\
\text { Standard }\end{array}$ & No & Level Value & Level Value Defintion & \multicolumn{3}{|c|}{ Case Image } \\
\hline \multirow{7}{*}{ Shape } & \multirow{4}{*}{$\begin{array}{l}\text { Prototype } \\
\text { categorizat } \\
\text { ion }\end{array}$} & $\begin{array}{l}1_{-} \\
1\end{array}$ & $\begin{array}{l}\text { Anthropomo } \\
\text { rphic type }\end{array}$ & $\begin{array}{l}\text { Express the external features of } \\
\text { human }\end{array}$ & 2 & 量 & tite \\
\hline & & 1 & $\begin{array}{l}\text { Zoomorphic } \\
\text { type }\end{array}$ & $\begin{array}{l}\text { Express the external features of } \\
\text { animals such as dogs, cats, and }\end{array}$ & 触 & & \\
\hline & & $\begin{array}{l}1- \\
3\end{array}$ & $\begin{array}{l}\text { Caricatured } \\
\text { type }\end{array}$ & $\begin{array}{l}\text { Express symbolic image of a } \\
\text { personality regardless of the } \\
\text { existence of the obiect. }\end{array}$ & & & \\
\hline & & $1_{-}$ & $\begin{array}{l}\text { Functional } \\
\text { object type }\end{array}$ & $\begin{array}{l}\text { Reflect task and purpose as much } \\
\text { as possible. Designed for } \\
\text { functional purpose. }\end{array}$ & & $i_{\infty}^{11}$ & 2 \\
\hline & \multirow{3}{*}{$\begin{array}{l}\text { Visual } \\
\text { realization }\end{array}$} & $\begin{array}{l}2- \\
1\end{array}$ & $\begin{array}{l}\text { Realistic } \\
\text { type }\end{array}$ & $\begin{array}{l}\text { Express the prototype's external } \\
\text { features as the same and } \\
\text { realistically. }\end{array}$ & $\therefore \quad$ & Wo & bis \\
\hline & & $\begin{array}{l}2- \\
2\end{array}$ & Iconic type & $\begin{array}{l}\text { Express the prototype's external } \\
\text { features as similar as possible }\end{array}$ & y. & tis & $i^{2}$ \\
\hline & & $\begin{array}{l}2- \\
3\end{array}$ & $\begin{array}{l}\text { Symbolic } \\
\text { type }\end{array}$ & $\begin{array}{l}\text { Appearance is almost abstract and } \\
\text { the prototype is symbolically } \\
\text { understood. }\end{array}$ & 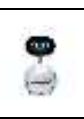 & Q & 0 \\
\hline Structure & $\begin{array}{l}\text { Level of } \\
\text { body }\end{array}$ & 3_1 & No division & $\begin{array}{l}\text { No visible division in the external } \\
\text { appearance }\end{array}$ & Q & (6) & 2 \\
\hline
\end{tabular}




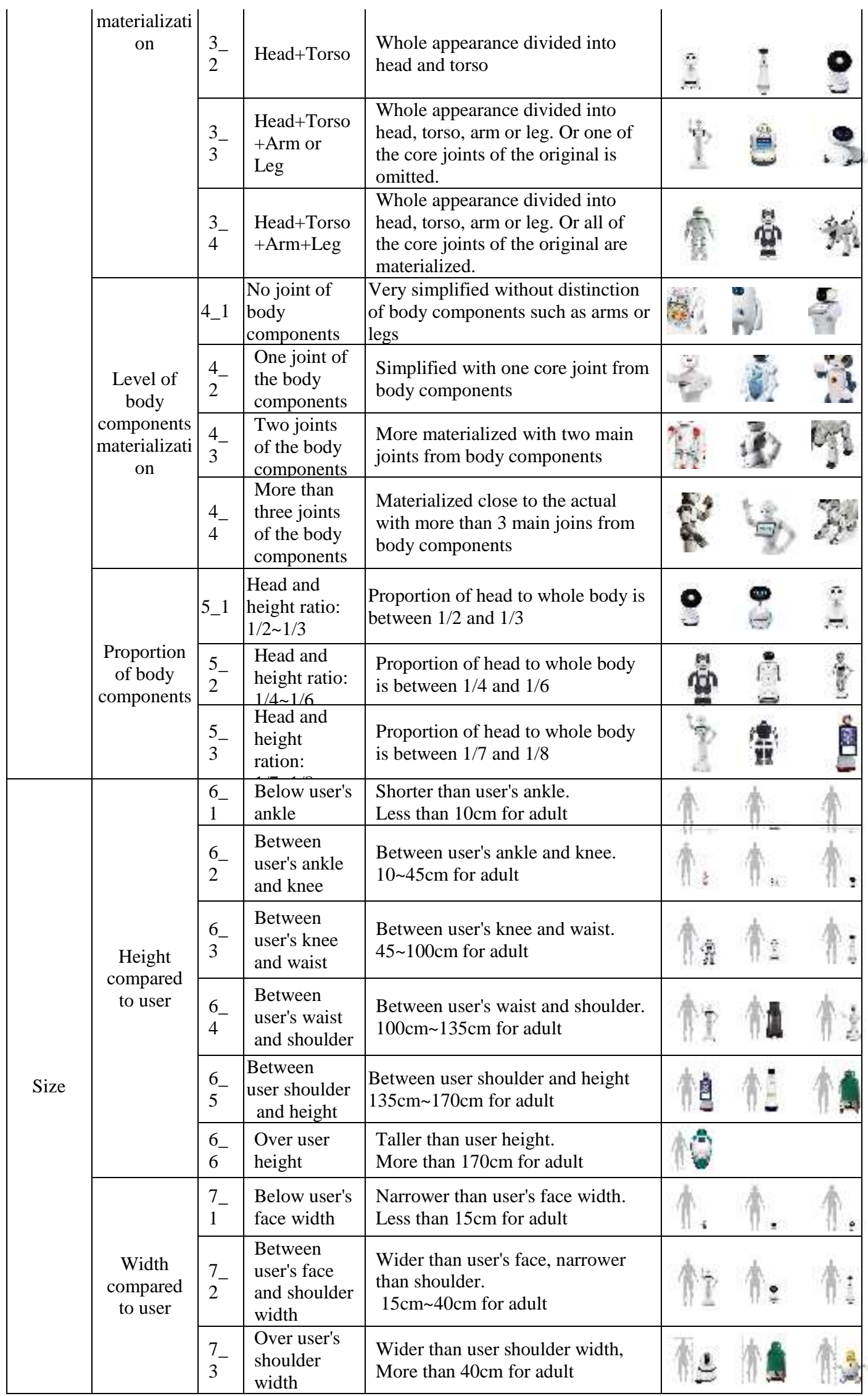




\section{User Experience Evaluation Survey on the Robot Interface Design Factors}

This research was conducted to measure the user experiences concerning the level values for each design factor of the robot appearance interface that had been organized through the reference researches and case studies earlier. Since the user experience itself has the whole aspect, it should have the user experience process as a frame work and then measure the user experience attributes that can be derived by each process and the results. Battarbee (2004) said that it can be divided into the product-centered, the interactioncentered and the human-centered perspectives[3]. The product-centered perspective is related to the product features and allows understanding the user experience in a practical dimension about the evaluation and classification. The interaction-centered perspective is related to the behavioral attributes between the human and the product; this helps understanding the user experience especially in the usage context. Lastly, the humancentered perspective is related to the human's attributes and this perspective is to understand the user experience in the aspect of the emotional and consequential experiences and the influential factors to them. In this research, the user experience were divided into the functional/service experience, interaction experience, and the human emotional experience and measured on the seven points of the Likert-type scale.

A website survey system was made and a group of 341 people participated including both male and female in between their 20s and 40s. In this survey, several images collected for the level values organized earlier were provided. The level value standards of the seven appearance interface factor and the 27 subordinate level values were investigated. The difference of the user experience in each level value was verified by using the One-Way ANOVA, One-Way Analysis of Variance) and the Scheffe verification was used to check the difference in each level.

\subsection{User Experience Evaluation on Prototype Categorization}

The average values of the 1-1. anthropomorphic type, 1-2.zoomorphic type, 1-3. caricatured type, and 1-4. functional object type, which were classified by the prototype categorization, have been compared. The difference of the prototype categorization in A)functional/service experience was statistically significant at where the p.value is greater than 0.001. 'Functional object' and 'human' were about the same level and fell into group 'a' while 'animal' and 'caricature' were about the same level and fell into group 'b'. B) Interactional experience also had a statistically significant difference of the p.value being greater than 0.001. 'Functional object' and 'human' were grouped in 'a' and were at the same level and 'animal' and 'caricature' were at the same level in the group 'b'. There was again a statistically significant difference in the C) emotional experience with the p.value is 0.017 . 'Functional object' in group ' $a$ ' and 'caricature' in group ' $b$ ' were at difference level while 'animal' and 'human' were at the same level as in group 'ab'. In other words, the classified level values can be grouped together in each experience type; however, in order to evaluate all the functional/service experience, the interaction experience, and the emotional experience, only classifying by the current level values can generate significant differences. 


\section{Table 3. Variance Analysis and Scheffe Verification of the Prototype Categorization}

\begin{tabular}{|c|c|c|c|c|c|c|c|c|c|c|c|c|c|c|}
\hline UX & No & mean & group & $\mathrm{F}$ & UX & No & mean & group & $\mathrm{F}$ & UX & No & mean & group & $\mathrm{F}$ \\
\hline \multirow{4}{*}{ A } & 1_1 & 4.733 & $\mathrm{a}$ & \multirow{4}{*}{$27.21 *$} & \multirow{4}{*}{ B } & 1_1 & 4.642 & $\mathrm{a}$ & \multirow{4}{*}{$14.52 *$} & \multirow{4}{*}{$\mathrm{C}$} & 1_1 & 4.846 & $a b$ & \multirow{4}{*}{$3.39 * *$} \\
\hline & 1_2 & 4.235 & b & & & $1 \_2$ & 4.283 & b & & & $1 \_2$ & 4.776 & $a b$ & \\
\hline & 1_3 & 4.145 & $\mathrm{~b}$ & & & 1_3 & 4.264 & $\mathrm{~b}$ & & & 1_3 & 4.623 & b & \\
\hline & 1_4 & 4.765 & $\mathrm{a}$ & & & 1_4 & 4.716 & a & & & 1_4 & 4.878 & $\mathrm{a}$ & \\
\hline
\end{tabular}

1. *p.value : $0.001<, * *$ p.value $: 0.05<.2$. scheffe $=2.799$, scheffe. $p=0$

\subsection{User Experience Evaluation on Visual Realization}

The average values of 2-1. realistic, 2-2. iconic, and 2-3. symbolic, which were classified by the visual realization, have been compared. The difference of the visual realization was statistically significant different in all A)functional/service experience, B)interaction experience and C)emotional experience with the p.value greater than 0.001 , but the 'iconic' and 'symbolic' were found to be at the same level in group 'a'. Thus, the visual realization was adjusted to be divided into 'realistic level' and 'iconic and symbolic level' rather than 'realistic level', 'iconic level' and 'symbolic level'.

\section{Table 4. Variation Analysis and Scheffe Verification of Visual Realization}

\begin{tabular}{|c|c|c|c|c|c|c|c|c|c|c|c|c|c|c|}
\hline UX & No & mean & group & $\mathrm{F}$ & UX & No & mean & group & $\mathrm{F}$ & $\mathrm{UX}$ & No & mean & group & $\mathrm{F}$ \\
\hline \multirow{3}{*}{ A } & $2 \_1$ & 3.978 & $\mathrm{~b}$ & \multirow{3}{*}{$2.45 *$} & \multirow{3}{*}{ B } & $2 \_1$ & 3.987 & $\mathrm{~b}$ & \multirow{3}{*}{$2.45^{*}$} & \multirow{3}{*}{$\mathrm{C}$} & $2 \_1$ & 4.07 & $\mathrm{~b}$ & \multirow{3}{*}{$2.45^{*}$} \\
\hline & $2 \_2$ & 4.493 & $\mathrm{a}$ & & & $2 \_2$ & 4.496 & $\mathrm{a}$ & & & $2 \_2$ & 4.801 & $\mathrm{a}$ & \\
\hline & $2 \_3$ & 4.356 & $\mathrm{a}$ & & & $2 \_3$ & 4.394 & $\mathrm{a}$ & & & $2 \_3$ & 4.647 & a & \\
\hline
\end{tabular}

1. *p.value $: 0.001<$. 2. scheffe $=2.451$, scheffe. $p=0$

\subsection{User Experience Evaluation on Level of Body Materialization}

The average values of 3-1. no division, 3-2. head and torso, 3-3. head, torso and arms or legs, and 3-4. head, torso, arms and legs, which were classified by the 'level of body materialization', have been compared. The difference of the level of body materialization was statistically significant in the A)functional/service experience with the p.value greater than 0.001 and 'head, torso, arms and legs' and 'head, torso and arms or legs' were at the same level in group 'a'. 'Head and torso' and 'no division' were also at the same level in group ' $b$ '. B) Interaction experience also had a statistically significant difference of the level of the body materialization with the p.value greater than 0.001 , but each level fell into all different groups. C) Emotional experience had a statistically significant difference as well with the p.value at 0.017 and each level was identified as different groups. Since the groups are all different in the functional/service experience, interaction experience, and emotional experience, it was determined to keep the classification by the current level values.

Table 3. Variation Analysis and Scheffe Verification of Level of Body Materialization

\begin{tabular}{|c|c|c|c|c|c|c|c|c|c|c|c|c|c|c|}
\hline$\overline{U X}$ & $\mathrm{No}$ & mean & group & $\mathrm{F}$ & $\overline{U X}$ & $\mathrm{No}$ & mean & group & $\mathrm{F}$ & $\mathrm{UX}$ & No & mean & group & $\mathrm{F}$ \\
\hline \multirow{4}{*}{ A } & 3_1 & 4.283 & $\mathrm{~b}$ & \multirow{4}{*}{$15.59 *$} & \multirow{4}{*}{ B } & 3_1 & 4.427 & $\mathrm{bc}$ & \multirow{4}{*}{$12.13^{*}$} & \multirow{4}{*}{$\mathrm{C}$} & 3_1 & 4.638 & $\mathrm{bc}$ & \multirow{4}{*}{$15.36^{*}$} \\
\hline & $3 \_2$ & 4.229 & $\mathrm{~b}$ & & & $3 \_2$ & 4.188 & $\mathrm{c}$ & & & $3 \_2$ & 4.472 & $\mathrm{c}$ & \\
\hline & 3_3 & 4.532 & $\mathrm{a}$ & & & $3 \_3$ & 4.452 & b & & & 3_3 & 4.721 & b & \\
\hline & 3_4 & 4.754 & $\mathrm{a}$ & & & 3_4 & 4.717 & $\mathrm{a}$ & & & 3_4 & 5.038 & $\mathrm{a}$ & \\
\hline
\end{tabular}

1. *p.value $: 0.001<.2$. scheffe $=2.799$, scheffe. $p=0$ 


\subsection{User Experience Evaluation on Level of Materialization of the Body Components}

The average values of 4-1. No joint of body parts, 4-2. One joint of the body components, 4-3. two joints of the body components, 4-4. more than three joints of the body components, which were classified by the level of materialization of the body components, have been compared. The difference of the level of materialization of the body components was all statistically significant in A)functional/service experience, B)interaction experience, and C)emotional experience with the p.value greater than 0.001 . 'Two joints of the body part element' and 'more than three joints of the body part element' fell into the group ' $a$ ' with the same level. Therefore, the four levels of the level of materialization of the body components were adjusted to three levels of 'no joint', 'one joint of the body part element', and 'more than two joints of the body part element'.

\section{Table 4. Variation Analysis and Scheffe Verification of Level of Materialization of the Body Components}

\begin{tabular}{|c|c|c|c|c|c|c|c|c|c|c|c|c|c|c|}
\hline UX & No & mean & group & $\bar{F}$ & UX & No & mean & group & $\mathrm{F}$ & UX & No & mean & group & F \\
\hline \multirow{4}{*}{ A } & 4_1 & 4.031 & $\mathrm{c}$ & \multirow{4}{*}{$53.422 *$} & \multirow{4}{*}{ B } & $4 \_1$ & 4.087 & $\mathrm{c}$ & \multirow{4}{*}{$38.845^{*}$} & \multirow{4}{*}{$\mathrm{C}$} & 4 & 4.387 & $\mathrm{c}$ & \multirow{4}{*}{$33.685^{*}$} \\
\hline & $4 \_2$ & 4.696 & $\mathrm{~b}$ & & & $4 \_2$ & 4.598 & $\mathrm{~b}$ & & & $4 \_2$ & 4.837 & $\mathrm{~b}$ & \\
\hline & 4_3 & 4.997 & $\mathrm{a}$ & & & 4_3 & 4.912 & $\mathrm{a}$ & & & 4_3 & 5.164 & $\mathrm{a}$ & \\
\hline & 4 & 5.208 & $\mathrm{a}$ & & & 4 4 & 5.072 & $\mathrm{a}$ & & & 4 4_ & 5.277 & $\mathrm{a}$ & \\
\hline
\end{tabular}

1. *p.value $: 0.001<.2$. scheffe $=2.799$, scheffe. $p=0$

\subsection{User Experience Evaluation on Proportion of the Body Components}

The average values of 5-1. Proportion of head to height is between $1 / 2$ and 1/3, 5-2. Proportion of head to height is between $1 / 4$ and 1/6, 5-3. Ratio of head to height is between $1 / 7$ and $1 / 8$, which were classified by the ratio of the body components, have been compared. A) Functional/service experience had a statistically significant difference in the proportion of head to height with the p.value at 0.021 and all the level values were all in different levels. However, there was no statistical significant difference in B) interaction experience and emotional experience with the p.value at 0.38 and 0.281 respectively. Because there was a difference in the functional/service experience, it was determined to keep the classification by the current level values.

Table 5. Variation Analysis and Scheffe Verification of Proportion of the Body Components

\begin{tabular}{|c|c|c|c|c|c|c|c|c|c|c|c|c|c|c|}
\hline UX & No & mean & group & F & UX & No & mean & group & $\mathrm{F}$ & UX & No & mean & group & F \\
\hline \multirow{3}{*}{ A } & 5_1 & 4.226 & b & \multirow{3}{*}{$3.888^{*}$} & \multirow{3}{*}{ B } & 5_1 & 4.252 & $\mathrm{a}$ & \multirow{3}{*}{0.969} & \multirow{3}{*}{ C } & 5_1 & 4.51 & $\mathrm{a}$ & \multirow{3}{*}{1.269} \\
\hline & $5 \_2$ & 4.381 & $a b$ & & & 5_2 & 4.364 & $\mathrm{a}$ & & & $5 \_2$ & 4.597 & $\mathrm{a}$ & \\
\hline & $5 \_3$ & 4.457 & $\mathrm{a}$ & & & 5_3 & 4.348 & $\mathrm{a}$ & & & 5_3 & 4.654 & a & \\
\hline
\end{tabular}

1. *p.value $: 0.05<.2$. scheffe $=2.451$, scheffe. $p=0$

\subsection{User Experience Evaluation on Height compared to User}

The average values of 6-1. below user's ankle, 6-2. between user's ankle and an adult's knee high level, 6-3. between the user's knee and waist level, 6-4. between the user's waist and shoulder level, 6-5. between the user's shoulder and height level, 6-6. over the user's height, which were classified by the height compared to the user, have been compared. The difference of the height compared to the user was statistically significant in all A)functional/service experience, B)interaction experience and C)emotional experience with the p.value greater than 0.001. 'Below the user's ankle', 
'between the user's ankle and an adult's knee high level', 'between the user's waist and shoulder' were found to be at the same level and all fell into the group 'ab'. Since the level values regarding the height are sequential items, the level of 'between the user's waist and shoulder level' which does not follow the order of sequence was to be kept separately. Therefore, the levels of the height compared to the user were adjusted to 'below the user's knee', 'between the user's knee and waist level', 'between the user's waist and shoulder level', 'between the user's shoulder and height level' and 'over the user's height'.

Table 6. Variation Analysis and Scheffe Verification of Height compared to User

\begin{tabular}{|c|c|c|c|c|c|c|c|c|c|c|c|c|c|c|}
\hline UX & No & mean & group & $\bar{F}$ & UX & No & mean & group & $\bar{F}$ & UX & No & mean & group & $\bar{F}$ \\
\hline \multirow{6}{*}{ A } & 6_1 & 4.282 & $a b$ & \multirow{6}{*}{$28.735^{*}$} & \multirow{6}{*}{ B } & 6_1 & 4.362 & $a b$ & \multirow{6}{*}{$33.933 *$} & \multirow{6}{*}{$\mathrm{C}$} & 6_1 & 4.522 & $a b$ & \multirow{6}{*}{$33.397 *$} \\
\hline & 6_2 & 4.343 & $a b$ & & & 6_2 & 4.394 & $a b$ & & & 6_2 & 4.666 & $a b$ & \\
\hline & 6_3 & 4.595 & $a$ & & & $6 \_3$ & 4.566 & $\mathrm{a}$ & & & 6_3 & 4.799 & $\mathrm{a}$ & \\
\hline & 6_4 & 4.499 & $a b$ & & & 6_4 & 4.424 & $a b$ & & & 6_4 & 4.616 & $\mathrm{ab}$ & \\
\hline & $6 \_5$ & 4.27 & $b$ & & & $6 \_5$ & 4.198 & $b$ & & & $6 \_5$ & 4.371 & $\mathrm{~b}$ & \\
\hline & 6_6 & 3.548 & c & & & 6_6 & 3.469 & c & & & 6_6 & 3.714 & c & \\
\hline
\end{tabular}

1. *p.value $: 0.001<.2$. scheffe $=3.331$, scheffe.p $=0$

\subsection{User Experience Evaluation on Width compared to User}

The average values of 7-1. Below an adult's face width, 7-2. Between an adult's face and shoulder level, and 7-3. Over an adult's shoulder, which were classified by the width compared to the user, have been compared. A)Functional/service experience regarding the difference of the width compared to the user had a statistically significant difference with the p.value greater than 0.001. 'Below the user's face width' and 'over the user's shoulders' fell into the group 'b' being at the same level. Both of B) Interaction experience and C) emotional experience also had a statistically significant difference with the p.value greater than 0.001 and all level values had different levels for both experiences. The classified level values can be grouped together in certain experience types; however, in order to evaluate all the functional/service experience, the interaction experience, and the emotional experience, it was determined to keep the classification by the current level values.

\section{Table 7. Variation Analysis and Scheffe Verification of Width compared to} User

\begin{tabular}{|c|c|c|c|c|c|c|c|c|c|c|c|c|c|c|}
\hline UX & No & mean & group & $\mathrm{F}$ & UX & No & mean & group & $\mathrm{F}$ & UX & No & mean & group & $\mathrm{F}$ \\
\hline \multirow{3}{*}{ A } & 7_1 & 3.933 & $\mathrm{~b}$ & \multirow{3}{*}{$25.257 *$} & \multirow{3}{*}{ B } & 7_1 & 4.028 & b & \multirow{3}{*}{$28.7 *$} & \multirow{3}{*}{$\mathrm{C}$} & 7_1 & 4.396 & $\mathrm{~b}$ & \multirow{3}{*}{$28.304 *$} \\
\hline & 7_2 & 4.425 & $\mathrm{a}$ & & & 7_2 & 4.462 & $\mathrm{a}$ & & & 7_2 & 4.773 & $\mathrm{a}$ & \\
\hline & 7_3 & 3.809 & b & & & 7_3 & 3.776 & $\mathrm{c}$ & & & 7_3 & 4.092 & $\mathrm{c}$ & \\
\hline
\end{tabular}

1. *p.value $: 0.001<$. 2 . scheffe $=2.451$, scheffe. $\mathrm{p}=0$

\section{Conclusion}

As the service robot market for general users expands, this research was conducted as a basis for systematization of robot interface design factors in terms of user experience. For this, the standards for the level values of the external appearance interface core design factors are summarized through existing reference studies and level values cases are 
summarized through case study analysis. Lastly, it was examined that whether the summarized values through the reference studies and case studies give meaningful differences in terms of user experience. Based on this, the level values for each design factors were suggested.

As a result of the research, it was found that 'prototype categorization, 'visual realization', 'level of body materialization', 'level of body components materialization', 'proportion of body components', 'height compared to user', and 'width compared to user', that are researched as the standards for dividing the level values, show differences in user experience, so they should be utilized as important categorizing factors.

Looking into the research result about the categorized detailed level values, the iconic and symbolic visual realization did not show a significant difference in terms of user experience. For the materialization of body, there was not any noticeable difference between the case of two joints of body components and the case with more than three. When the height of robot compared to user is below user's ankle or between use's ankle and knee, there was any difference found. Thus, the researched subordinate 27 level values are reorganized into 24 level values after deleting three.

In the field of robot interface design, the multidisciplinary consideration on the factor classification is very important as the need for the standardization of the robot design foundation research is increasing. In this research, the concept of user experience, which is already approved to have market competitiveness in HCI research, was suggested as a core standard for service robot interface design. The robot interface design factors and the systematization of the level values in terms of user experience will be utilized a design library for the social service robot industry as well as the base research for further research in academic field.

\section{Acknowledgments}

This research was supported by Basic Science Research Program through the National Research Foundation of Korea(NRF) funded by the Ministry of Education(No.2017R1A6A3A11031044).

This paper is a revised and expanded version of a paper entitled "Social Robot's Appearance Interface Design Factor Research" presented at The 14th 2017 International Interdisciplinary Workshop, Daejeon, Korea, (2017) December 21-23.

\section{References}

[1] C. L. Breazeal, "Designing Sociable Robot", MIT Press, (2002).

[2] M. S. Kim, K. M. Oh, J. H. Kim and S. N. Kwak, "Robot Design and Major Research Issues", Korea robotics society review, vol. 3, no. 3, (2006), pp. 50-60.

[3] K. Battarbee, "Co-experience: Understanding user experiences insocial interaction. Unpublished doctoral dissertation", University of Artand Design Helsinki, (2004).

[4] K. S. Haring, K. Watanabe and C. Mougenot, "The influence of robot appearance on assessment", Proceedings of the 8th ACM/IEEE international conference on Human-robot interaction, (2013).

[5] T. Fong, I. Nourbakhsh and K. Dautenhahn, "A survey of socially interactive robots", Robotics and autonomous systems, vol. 42, no. 3, (2003), pp. 143-166.

[6] C. Bartneck and J. Forlizzi, "A design-centred framework for social human-robot interaction", Proceedings of Robot and Human Interactive Communication, 13th IEEE International Workshop, (2004).

[7] M. Blow, K. Dautenhahn, A. Appleby, C. L. Nehaniv and D. C. Lee, "Perception of robot smiles and dimensions for human-robot interaction design", Proceeding of In Robot and Human Interactive Communication, 2006. ROMAN 2006. The 15th IEEE International Symposium, (2006) September, pp. 469-474.

[8] E. Shin, S. Kwak and M. S. Kim, "Body Feature of Robot according to its Appearance Classification", Proceeding of KSDS Conference, (2007) October 28-29.

[9] H. Ryu, S. S. Kwak and M. Kim, "A Study on External Form Design Factors of Teaching Assistant Robots for the Elementary School - With Emphasis on the Impression According to Body Feature -", Archives of Design Research, (2007), pp. 107-118. 
[10] A. Paiva, I. Leite and T. Ribeiro, "Emotion modelling for social robots", Oxford: Oxford University Press, (2012).

[11] I. Bae and J. Han, "Does Height Affect the Strictness of Robot Assisted Teacher?", Proceedings of the Companion of the 2017 ACM/IEEE International Conference on Human-Robot Interaction, (2017) March 73-74.

[12] I. Rae, L. Takayama and B. Mutlu, "The influence of height in robot-mediated communication", Proceedings of Human-Robot Interaction (HRI), 2013 8th ACM/IEEE International Conference, (2013) March 1-8.

[13] K. Lee, J. Park and Y. Ryoo, "Development of Child-Sized Humanoid Robot", Journal of Korean Institute of Intelligent Systems, vol. 23, no. 1, (2013), pp. 24-28.

[14] S. E. Chung and H. Y. Ryoo, "Social Robot's Appearance Interface Design Factor Research", International Journal of Artificial Intelligence and Applications for Smart Devices, vol. 5, no. 2, (2017), pp. 7-12.

\section{Authors}

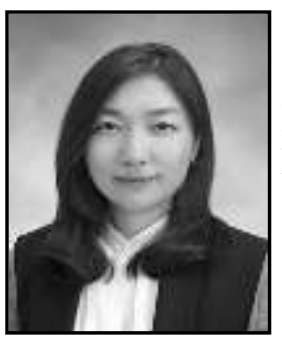

Seung Eun Chung, is a research professor in the Dept. of Content Convergence at Ewha Womans University. She received $\mathrm{Ph} . \mathrm{D}$ in Media Design from the Division of Digital media at Ewha Womans University. Her research areas are user experience design, graphic user interface design, and so on.

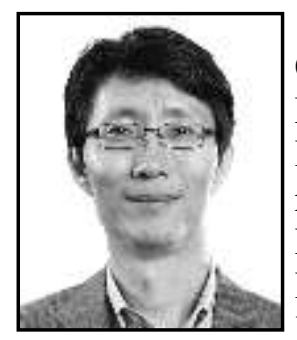

Han Young Ryoo, is a professor in the Dept. of Content Convergence at Ewha Womans University. He received B.S. \& M.F.A. degrees in Industrial Design from KAIST (Korea Advanced Institute of Science and Technology) \& Kookmin University respectively, and D.Sc. in Interactive Multimedia from the Department of Computer Science at George Washington University. $\mathrm{He}$ has also worked as an editor of Journal of the HCI Society of Korea. His research areas are user experience design, user interface design, usability evaluation, and so on. 
International Journal of Advanced Science and Technology

Vol.113 (2018) 